\title{
MUDANÇA DE COMPORTAMENTO DE EMPREENDEDORES: UMA ANÁLISE DOS TIPOS DE EMPREENDEDOR ANTES, DURANTE E DEPOIS DO INSUCESSO EMPRESARIAL
}

\author{
CHANGE IN BEHAVIOR OF ENTREPRENEURS: AN ANALYSIS ABOUT THE TYPES OF ENTREPRENEUR \\ BEFORE, DURING AND AFTER THE BUSINESS FAILURE
}

DOI: http://dx.doi.org/10.12712/rpca.v6i4.215

Italo Fernando Minello

italo.minello@uol.com.br

Departamento de Ciências Administrativas da Universidade Federal de Santa Maria (UFSM)- Santa

Maria - RS - Brasil

Laura Alves Scherer

laurascherer@ymail.com

Departamento de Ciências Administrativas da Universidade Federal de Santa Maria (UFSM)- Santa Maria - RS - Brasil

\section{Resumo}

Este artigo tem como objetivo analisar a mudança de tipo e de características comportamentais de empreendedores antes, durante e depois do insucesso empresarial. A sustentação teórica para este artigo teve como enfoque concepções sobre empreendedor, suas tipologias e características comportamentais, e o insucesso empresarial. A presente pesquisa caracteriza-se como qualitativa, do tipo exploratório e descritivo, e utiliza a entrevista semiestruturada como instrumento de coleta de dados. As unidades de análise são representadas por sete empreendedores que vivenciaram o insucesso empresarial. A análise dos dados foi realizada a partir de quatro passos de análise caracterização do tipo de empreendedor, definição das categorias de análise a priori, sumarização da mudança de tipo de empreendedor no período de pesquisa, e aplicação da técnica de análise de conteúdo. Foram definidas três categorias a priori com base no foco da classificação das tipologias de cada autor: forma de atuação (VESPER, 1980); personalidade (MINER, 1996); e valores e pensamento empresarial (FILION, 1999). Como principal resultado destaca-se que o comportamento dos empreendedores entrevistados foi influenciado ao enfrentar a adversidade do insucesso empresarial, repercutindo em sua forma de atuação, personalidade, e, valores e pensamento empresarial. A partir disso, as mudanças em suas características comportamentais provocaram alteração em seu tipo de empreendedor nos diferentes momentos de pesquisa - antes, durante e depois do insucesso empresarial.

Palavras-chave: Empreendedor. Comportamento Empreendedor. Tipologia. Tipos de Empreendedor. Insucesso Empresarial.

\section{Abstract}

This paper aims to analyze the change of entrepreneur's behavioral characteristics before, during and after business failure. The theoretical framework was covered by the following topics: entrepreneur and its types, and entrepreneur's behavior face the business failure. The types used were based on entrepreneur's behavioral characteristics and supported by the following authors of the entrepreneurship literature: Vesper (1980), Miner (1996) and Filion (1999). This study is characterized as exploratory, descriptive and uses semi-structured interviews as data collection instrument. The analysis unit are seven entrepreneurs who experienced the disruption of its business in Sao Paulo. The analysis of behavioral changes and typology of entrepreneurs was performed in a qualitative way, by applying the technique of content analysis. Three categories were defined a priori based on the focus of classification of types of each author: performance (Vesper, 1980), personality (MINER, 1996), and values and entrepreneurial thinking (Filion, 1999). The main result emphasized that behavior of the entrepreneurs interviewed was affected when facing adversity of business failure, influencing their performance, personality, values and entrepreneurial thinking. From this, the changes in their behavioral characteristics caused changes in their entrepreneur's type in the different 
times of research - before, during and after business failure.

Keywords: Entrepreneur. Entrepreneur Behavior. Typology. Types of Entrepreneur. Business Failure. 


\section{Introdução}

As pesquisas acadêmicas na área de empreendedorismo cresceram bastante nas últimas décadas (FLECK, 2009). Para os investigadores desta área, o empreendedor é um elemento importante a ser estudado no contexto da mudança organizacional, pois suas características comportamentais também podem ser alteradas pela tranformação do ambiente. Neste artigo, essas alterações estão direcionadas para a análise do comportamento do empreendedor diante da transição provocada pelo insucesso empresarial. Contudo, a maioria dos estudos organizacionais de novos empreendimentos tem como foco os casos de sucesso, sendo limitadas as pesquisas sobre insucesso (ZACHARAKIS, MEYER e DECASTRO, 1999).

Nesse sentido, o insucesso é algo para o qual o empreendedor não está preparado (FLECK, 2009). Cabe salientar, que o empreendedor que conduz a organização precisa adaptar tanto o seu negócio quanto suas características e seus comportamentos às mudanças internas e externas, que podem influenciar no direcionamento para o sucesso ou insucesso do seu empreendimento (ZACHARAKIS, MEYER e DECASTRO, 1999). Para facilitar o estudo dessas características, muitos autores desenvolvem tipologias, propostas mediante a combinação de particularidades comportamentais do empreendedor diante o seu negócio, as quais também norteiam o propósito deste estudo.

Apesar de o insucesso ser um tema instigante e desafiador (FLECK, 2009; DOTLICH; CAIRO, 2003), verifica-se que é um tema ainda pouco explorado na literatura, por esse motivo este estudo pretende contribuir para a compreensão das peculiaridades das características comportamentais do empreendedor diante das mudanças inerentes o mundo dos negócios, como no caso do insucesso empresarial. Por outro lado, percebe-se que o insucessso é uma temática com crescente interesse por parte dos pesquisadores, conforme salienta GEM (2010), o que evidencia o objetivo deste estudo: analisar a mudança de tipo e de características comportamentais de empreendedores antes, durante e depois do insucesso empresarial. Nesse sentido, ressalta-se que este trabalho tem como base as experiências de insucesso de empreendedores e como foco de estudo as suas mudanças de comportamento e de tipologia de empreendedor apresentadas por Vesper (1980), Miner (1996) e Filion (1999).

No intuito de compreender melhor essa temática, a seguir apresenta-se uma breve revisão da literatura sobre empreendedor e suas tipologias e sobre o comportamento empreendedor diante do insucesso empresarial.

\section{Empreendedor e suas Tipologias}

Um dos primeiros autores a refletir sobre a atividade empresarial foi Schumpeter (1997), em sua obra "Teoria do Desenvolvimento Econômico". Para o autor, o empreendedor é considerado como aquele que quebra a ordem e inova, introduz novos produtos e serviços pela criação de formas de organização ou pela exportação de novos recursos, identifica oportunidades no mercado, promovendo o desenvolvimento e o crescimento econômico.

Dornelas (2008) amplia o pensamento de Schumpeter (1997) quando acrescenta ao conceito variáveis que envolvem as funções, atividades e ações associadas à criação de novas empresas por parte do empreendedor. A identificação do empreendedor como um indivíduo que possui características inovadoras, que transforma conhecimento e bens em novos produtos, pode ter se tornado algo prático para sociedade. Contudo, Baron e Shane (2007) ressaltam que as definições são sempre traiçoeiras e, no que se refere ao caso do empreendedor, essa tarefa torna-se mais complexa, pois se pode verificar a existência de uma falta de consenso sobre sua 
definição na literatura.

Nesse sentido, evidencia-se que, assim como o ser humano é singular em sua essência (CASADO, 2002), o empreendedor também o é no que se refere a sua atuação dentro do contexto organizacional. Resende (2008) relata que os indivíduos são em sua essência, seres singulares, dotados de comportamento diferenciados. Esses comportamentos são distintos devido a diversos fatores internos de personalidade, dentre eles: a variedade fisiológica, os temperamentos diferentes, as aptidões distintas, as diferentes habilidades desenvolvidas ao longo da vida dependendo das situações, as dificuldades e os desafios (RESENDE, 2008). Além disso, de acordo com Hisrich, Peters e Shepherd (2009), é frequente os empreendedores tomarem decisões de alto risco, em ambientes de intensa pressão de tempo e de investimento emocional significativo. Para estes autores, a forma de pensar de empreendedores inseridos em ambientes com tais características apresentam comportamentos distintos daqueles de quando a natureza de um problema é bem compreendida, quando existe disponibilidade de tempo e de procedimentos racionais para solucioná-lo.

Segundo Zampier e Takahashi (2011), não é possível enquadrar os empreendedores em um padrão, no entanto, é possível definir alguns tipos. Desta forma, considerando-se a diversidade de características comportamentais, percebeu-se com base nas pesquisas de diferentes investigadores, que existiam certas similitudes comportamentais na forma de atuação dos empreendedores, proporcionando um agrupamento dessas características, gerando diferentes tipologias.

No intuito de contribuir para a compreensão desse agrupamento são apresentadas três tipologias baseadas no comportamento dos empreendedores na perspectiva de Vesper (1980), de Miner (1996) e de Filion (1999). A escolha dessas tipologias se deu em função de que os referidos autores têm como foco de suas abordagens as características comportamentais.

Nesse sentido, buscando proporcionar uma visão mais abrangente da relação entre as características comportamentais de empreendedores com a perspectiva teórica sobre tipologia, apresenta-se a primeira tipologia abordada neste artigo. Desenvolvida por Vesper (1980), esta tipologia apresenta onze categorias e tem como foco a forma de atuação dos empreendedores.

\section{Quadro 1: Tipologia do Empreendedor na perspectiva de Vésper (1980)}

\begin{tabular}{|c|c|}
\hline Tipo de Empreendedor & Características Comportamentais \\
\hline Autônomo & Executam seus serviços pessoalmente, baseando-se em habilidade técnica. \\
\hline Formador de Equipes & $\begin{array}{c}\text { Contratam outras pessoas e delegam tarefas, formando equipes, } \\
\text { percebendo uma possível vantagem na expansão do negócio. }\end{array}$ \\
\hline Inovador Independente & Criadores de novos produtos, que criariam empresas para desenvolvê-los. \\
\hline Multiplicador de Padrão & Reconhecem um negócio, passível de ser multiplicado visando a obter \\
\hline $\begin{array}{c}\text { Explorador de Economia } \\
\text { de Escala }\end{array}$ & $\begin{array}{c}\text { Criam seus negócios baseados em preços menores obtidos devido à } \\
\text { economia de escala, localização em áreas mais baratas e/ou com impostos } \\
\text { menores. }\end{array}$ \\
\hline $\begin{array}{c}\text { Agregador de Capital } \\
\text { Captam recursos de diversas fontes para bancar a operação de bancos, }\end{array}$ \\
\hline
\end{tabular}


Mudança de comportamento de empreendedores: uma análise dos tipos de empreendedor antes, durante e depois do insucesso empresarial

\begin{tabular}{|c|c|}
\hline & seguradoras entre outras. \\
\hline Aquisidor & Optam por adquirir negócios que já estão em processo de operação. \\
\hline $\begin{array}{c}\text { Especialista de Compra e } \\
\text { Venda }\end{array}$ & $\begin{array}{r}\text { Compram empresas em dificuldades, as recuperam e depois as vendem por } \\
\text { um preço maior. }\end{array}$ \\
\hline $\begin{array}{c}\text { Formador de } \\
\text { Conglomerados }\end{array}$ & $\begin{array}{r}\text { Trabalham para obter controle acionário de uma empresa para, a partir } \\
\text { desta, adquirir o controle de outras empresas. }\end{array}$ \\
\hline $\begin{array}{c}\text { Especulador } \\
\text { Manipulador de Valor } \\
\text { Aparente }\end{array}$ & $\begin{array}{r}\text { Adquirem bens ou empresas baratas, melhorando sua aparência ou índices } \\
\text { financeiros para revendê-los com elevação no preço. }\end{array}$ \\
\hline
\end{tabular}

Fonte: adaptado de Vesper (1980)

A segunda tipologia utilizada foi desenvolvida por Miner (1996), a partir das pesquisas de Collins e Moore (1965) e de Smith (1967), a qual sustenta a ideia de que existe relação direta entre a personalidade do indivíduo e o potencial para o sucesso empresarial. 0 autor desenvolveu um estudo com cem empreendedores aplicando testes psicológicos e questionários, que resultaram em uma classificação de quatro tipos de empreendedores.

\section{Quadro 2: Tipologia do Empreendedor na perspectiva de Miner (1996)}

\begin{tabular}{|c|c|}
\hline $\begin{array}{c}\text { Tipo de } \\
\text { Empreendedor }\end{array}$ & Características Comportamentais \\
\hline $\begin{array}{c}\text { Empreendedor } \\
\text { Pessoal }\end{array}$ & $\begin{array}{c}\text { Procura ser bom em tudo o que faz, possui iniciativa e comprometimento com } \\
\text { a organização, procura trabalhar baseado no planejamento de objetivos } \\
\text { pessoais. }\end{array}$ \\
\hline $\begin{array}{c}\text { Especialista Gerador } \\
\text { de Ideia }\end{array}$ & $\begin{array}{c}\text { Busca a inovação, procura atingir as estratégias da empresa através de novos } \\
\text { produtos, novos nichos e novos processos. Possui um bom grau de } \\
\text { inteligência, desejo por ideias e tenta não correr risco. }\end{array}$ \\
\hline $\begin{array}{l}\text { Empático } \\
\text { Supervendedor }\end{array}$ & $\begin{array}{c}\text { Acredita que a via adequada para o sucesso empresarial é a força das vendas, } \\
\text { leva em consideração os processos sociais, o bom relacionamento com os } \\
\text { indivíduos, procura compreendê-los }\end{array}$ \\
\hline Verdadeiro Gestor & $\begin{array}{c}\text { É aquele que procura se adaptar para gerir um cargo de alta chefia, tem o } \\
\text { desejo de poder, relaciona-se de maneira satisfatória com as autoridades, } \\
\text { busca a competição empresarial, além de possuir uma boa capacidade } \\
\text { decisória. }\end{array}$ \\
\hline
\end{tabular}

Fonte: adaptado de Miner (1996)

A terceira tipologia, definida por Filion (1999), tem como foco proprietários-gerentes de pequenas empresas. 0 resultado de sua pesquisa apresenta a identificação de seis tipos diferentes de empreendedores, os quais são apresentados no quadro 3. 


\section{Quadro 3: Tipologia do Empreendedor na perspectiva de Filion (1999)}

\begin{tabular}{|c|c|}
\hline $\begin{array}{c}\text { Tipo de } \\
\text { Empreendedor }\end{array}$ & Características Comportamentais \\
\hline Lenhador & $\begin{array}{l}\text { Caracteriza-se por gostar de fazer as coisas, sente-se como se estivesse perdendo } \\
\text { tempo quando têm de falar com pessoas, enquanto o empregador prefere as pessoas } \\
\text { que trabalham durante muitas horas como ele mesmo, sendo que a cultura } \\
\text { organizacional do seu empreendimento está voltada para a produção. }\end{array}$ \\
\hline Sedutor & $\begin{array}{l}\text { Entrega-se de maneira completa e emocional aos negócios, mas seu entusiasmo } \\
\text { nunca dura muito. Cria negócios e logo os vende, gosta que as coisas aconteçam } \\
\text { rapidamente. Procura onde e como ter lucros com o menor esforço possível. }\end{array}$ \\
\hline Jogador & $\begin{array}{l}\text { Percebe o esporte e o lazer como elemento vital em sua vida. Considera a empresa } \\
\text { um suporte financeiro, um meio de ganhar o suficiente para fazer o que realmente } \\
\text { quer. Opta por campos de atuação sazonais. Não está de maneira absoluta } \\
\text { comprometido emocionalmente com o negócio. }\end{array}$ \\
\hline Hobbysta & $\begin{array}{c}\text { Dedica toda a sua energia e o tempo livre aos negócios. Freqüentemente possui outro } \\
\text { emprego oficial, mas só o mantêm como um apoio financeiro para seu negócio. } 0 \\
\text { negócio é seu hobby. É nele que vê a possibilidade de auto-realização, assim investe } \\
\text { todos os recursos para desenvolvê-lo. }\end{array}$ \\
\hline Convertido & $\begin{array}{l}\text { Procura alguma coisa com que se realize, quando encontra o que buscava, sua vida } \\
\text { gira em torno dessa descoberta. Prefere ver a si mesmo como uma pessoa } \\
\text { particularmente superior, ao invés de ver os resultados, gostam de estar no controle, } \\
\text { por isso têm dificuldade de delegar até que a outra pessoa prove merecer confiança. }\end{array}$ \\
\hline Missionário & $\begin{array}{l}\text { Conhece muito bem o produto e o mercado. Leva em consideração a evolução e o } \\
\text { aprendizado dos indivíduos, compreende o negócio como um sistema social, acredita } \\
\text { que os resultados dependem do trabalho em equipe. Delega ao máximo, participa de } \\
\text { atividades em força-tarefa, onde possam escutar discutir e trocar experiências. }\end{array}$ \\
\hline
\end{tabular}

Fonte: adaptado de Filion (1999).

Para Filion (1999) as tipologias possibilitam uma base para a compreensão dos valores e do pensamento empresarial, bem como, do comportamento do empreendedor. Porém, deixa claro que nenhuma tipologia é completamente suficiente para cobrir todos os tipos de empreendedores, pois cada caso pode ser considerado único.

Nesse sentido, com o intuito de relacionar as características comportamentais de empreendedores e de entender o contexto do fracasso, vivenciado pelos empreendedores entrevistados, apresenta-se a seguir algumas reflexões sobre o insucesso empresarial e sobre seu comportamento diante dele.

\section{Insucesso Empresarial e Comportamento do Empreendedor diante dessa Adversidade}

Na literatura sobre negócios e ambiente empresarial é possível encontrar inúmeros casos e estudos de empresas que obtiveram sucesso (GEM, 2010), no entanto, em relação ao insucesso empresarial, na visão de Zacharakis, Meyer e Decastro (1999) percebe-se que este tema ainda é pouco explorado. Nesse sentido, Robinson (2007) relata que o fracasso nos empreendimentos é um importante aspecto a ser estudado, pois influencia diretamente a economia e a sociedade como um todo, porém são de difícil análise devido à diversidade de definições de fracasso nos negócios, às várias causas de descontinuidade e à falta de dados 
abrangentes sobre o tema.

Com relação ao conceito de insucesso empresarial, Bruno, Mcquarrie e Torgrimson (1992) o definem como uma descontinuidade do negócio, que pode ser oriunda de várias causas, dentre elas, os autores destacam: problemas legais, disputas na sociedade e morte ou mudança de interesse. Neste artigo, adotou-se essa perspectiva teórica, em função do seu alinhamento com o objetivo do trabalho.

No estudo realizado por Bruno, Leidecker e Harder (1986), as causas do insucesso empresarial percebidas pelos empreendedores foram categorizadas como produto/mercado e financeiras, oriundas de fora da organização e; gerenciais, relacionadas ao contexto interno das organizações. Cabe salientar que a partir da pesquisa de Bruno, Leidecker e Harder (1986), pode-se evidenciar que, mesmo em épocas distintas, os fatores que causam o insucesso são apontados por problemas externos ou de gestão e que os empreendedores e financiadores de novos empreendimentos também compartilham esse pensamento.

Tanto advindo por fatores externos quanto por problemas na gestão, o insucesso do negócio também vai influenciar ou ser influenciado pelas características do empreendedor e pelo seu comportamento. Na visão de Pereira (1995), o que diferencia fracasso do sucesso são as características, capacidades e habilidades individuais do empreendedor diante da adversidade.

Baseado em pesquisa realizada com dirigentes norte-americanos, Finkelstein $(2004,2007)$, corrobora a essa visão comportamental do empreendedor diante do insucesso, ao afirmar que a crença do líder de possuir o total domínio de seu ambiente utilizando as pessoas como instrumento, é um dos hábitos do executivo malsucedido, assim como a completa identificação do líder com a empresa, o que faz com que cumpram suas ambições pessoais utilizando-se dos recursos corporativos.

Segundo Finkelstein $(2004,2007)$, a razão da maioria dos fracassos pode não estar na inexistência de capacidade, mas na percepção, por parte de seus dirigentes, de sua excelência e na autoconfiança, a qual pode provocar uma dificuldade de adaptação da empresa às mudanças ambientais. Dessa forma, Dotlich e Cairo (2003), fazem referência a questão comportamental e perceptiva por parte dos executivos que falham, as causas dos problemas estão relacionadas ao que eles fazem, as suas decisões e quem eles são.

Com base no que foi exposto, pode-se perceber que as características comportamentais do indivíduo influenciam no seu comportamento empreendedor diante de seu negócio, influenciando no sucesso ou fracasso de seu empreendimento.

\section{Método de Pesquisa}

Esta pesquisa caracteriza como qualitativa, descritiva e exploratória. A abordagem qualitativa justifica-se por ser adequada em situações em que se busca obter informações de indivíduos, comunidades, contextos, variáveis ou situações em profundidade, nas próprias palavras, definições ou termos dos indivíduos em seu contexto (SAMPIERI et al., 2006); como no caso de mudanças de comportamento e de tipologia de empreendedores em situações de insucesso empresarial.

No que diz respeito à característica descritiva, Sampieri et al., (2006) relatam que estes estudos são úteis quando se pretende especificar propriedades, características e perfis de pessoas, grupos e comunidades. Com relação ao estudo de cunho exploratório, na visão de Sampieri et al. (2006), este é utilizado quando se busca examinar um tema ou problema de 
pesquisa pouco estudado, que apresenta dúvidas ou ainda foi pouco abordado. Nesse sentido, o delineamento descritivo e exploratório justifica-se para este estudo, em função de seu objetivo e da escassez de referencial teórico sobre o tema.

Considerando-se o objetivo deste estudo - analisar a mudança de tipo e de características comportamentais de empreendedores antes, durante e depois do insucesso empresarial - e a particularidade necessária aos entrevistados para participarem da pesquisa, optou-se pela utilização de unidades de análise. Nesse sentido, o grupo de entrevistados foi formado por sete empreendedores que vivenciaram o insucesso empresarial, que conseguiram superá-lo, que se predispuseram a falar sobre a experiência do fracasso. Os entrevistados, considerados como unidade de análise, tiveram seus empreendimentos descontinuados na Grande São Paulo e foram denominados no decorrer deste artigo como Entrevistado 1 (E1), Entrevistado 2 (E2), e assim sucessivamente.

Com relação à coleta de dados, o instrumento utilizado foi entrevista semiestruturada, sendo as mesmas gravadas e transcritas, com duração de aproximadamente uma hora e trinta minutos. Essas entrevistas foram realizadas por meio da aplicação de um roteiro de entrevista, o qual permitiu o levantamento de dados nos diferentes momentos de pesquisa antes, durante e depois do insucesso empresarial. Posteriormente foi aplicada a técnica de análise de conteúdo, especificamente a análise categorial e de enunciação. De acordo com Bardin (2010) a análise de conteúdo é composta por técnicas de análise das comunicações, que por meio de procedimentos sistemáticos busca obter indicadores que permitam a inferência de conhecimentos relativos à descrição do conteúdo das mensagens, permitindo a inferência de conhecimento sobre estas mensagens.

As categorias de análise foram definidas a priori a partir do foco utilizado por Vesper (1980), Miner (1996) e Filion (1999) para classificar suas tipologias de empreendedor, conforme apresentado no quadro 4.

\section{Quadro 4: Quadro de referência para definição das categorias de análise a priori}

\begin{tabular}{|c|c|c|c|}
\hline Autor & Foco & Tipologia & Principais Características \\
\hline \multirow{11}{*}{$\begin{array}{l}\text { Vésper } \\
\text { (1980) }\end{array}$} & \multirow{11}{*}{$\begin{array}{l}\text { Forma de } \\
\text { atuação }\end{array}$} & Autônomo & Habilidade Técnica \\
\hline & & Formador de Equipes & Delegar tarefa e forma equipes \\
\hline & & Inovador Independente & Criar de produtos para terceiros \\
\hline & & Multiplicador de padrão & Reconhecer negócio passivel a multiplicação de lucro \\
\hline & & Explorador de Economia de Escala & Investir em negócios de menores preços \\
\hline & & Agregador de Capital & Captar recursos de diversas fontes \\
\hline & & Aquisidor & Adquirir negócios já em operação \\
\hline & & Especialista de Compra e Venda & Adquirir negócio para vender sobre um preço maior \\
\hline & & Formador de Conglomerados & Controlar ações \\
\hline & & Especulador & Comprar e vender commodities \\
\hline & & Manipulador de Valor Aparente & Comprar empresas de baixo valor e vender por maior valor \\
\hline \multirow{4}{*}{$\begin{array}{l}\text { Miner } \\
(1996)\end{array}$} & \multirow{4}{*}{$\begin{array}{l}\text { Personalidade e } \\
\text { potencial para o } \\
\text { sucesso }\end{array}$} & Empreendedor pessoal & Focar em seus interesses pessoais \\
\hline & & Especialista Gerador de Ideia & Inovar sem riscos \\
\hline & & Empático Supervendedor & Bom relacionamento \\
\hline & & Verdadeiro Gestor & Competitividade e capacidade decisória \\
\hline \multirow{6}{*}{$\begin{array}{l}\text { Filion } \\
\text { (1999) }\end{array}$} & \multirow{6}{*}{$\begin{array}{l}\text { Valores e } \\
\text { pensamento } \\
\text { empresarial }\end{array}$} & Lenhador & Focar na produção \\
\hline & & Sedutor & Entusiasta e fugaz na concretização \\
\hline & & Jogador & A empresa é seu suporte financeiro \\
\hline & & Hobbysta & Auto-realização \\
\hline & & Convertido & Cético e controlador \\
\hline & & Missionário & Realista e social \\
\hline
\end{tabular}


Fonte: elaborado pelos autores com base em Vesper (1980), Miner (1996) e Filion (1999).

Sendo assim, a partir do quadro de referência (quadro 4), definiram-se três categorias de análise a priori: forma de atuação (VESPER,1980); personalidade e potencial para o sucesso (MINER ,1996); e, valores e pensamento empresarial (FILION,1999). Para atender ao objetivo deste artigo, as categorias foram analisadas em três momentos - antes, durante e depois do insucesso empresarial (IE), conforme apresentado na figura 1.

\section{Figura 1: Categorias de análise a priori}

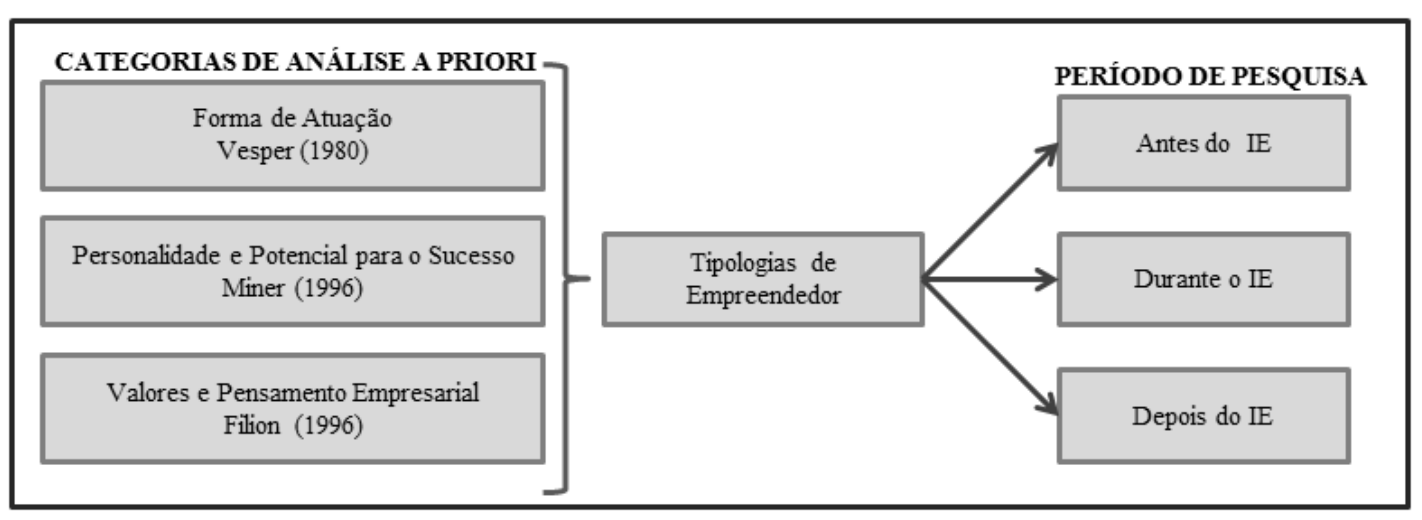

Fonte: elaborado pelos autores com base em Vesper (1980), Miner (1996) e Filion (1999).

A partir do exposto até então, definiram-se seguintes os passos de análise adotados para esta pesquisa:

1) Caracterização do tipo de empreendedor dos entrevistados - antes, durante e depois do insucesso empresarial;

2) Apresentação das categorias de análise com o enquadramento de cada entrevistado no tipo de empreendedor encontrado nos três períodos de pesquisa - quadro 5.

3) Análise das Categorias Definidas a Priori - forma de atuação; personalidade e potencial para o sucesso; e valores e pensamento empresarial -, por meio da análise categorial e de enunciação.

4) Discussão dos resultados, a partir da síntese da mudança de tipo de empreendedor nos entrevistados - quadro 6.

\section{Análise dos Resultados}

A análise das mudanças de comportamento dos empreendedores entrevistados está centrada nas características comportamentais desses indivíduos, nos diferentes momentos de pesquisa - antes, durante e depois do insucesso empresarial. A partir disso, considerando-se a perspectiva teórica apresentada neste artigo, é possível perceber que cada um dos tipos de empreendedor, evidenciados nas abordagens de Vesper (1980), Miner (1996) e Filion (1999), é definido pelos autores com base nas características comportamentais empreendedoras. Dessa forma, buscou-se, então, analisar o comportamento dos empreendedores entrevistados a partir do foco de cada tipologia - forma de atuação; personalidade e potencial para o sucesso; e, valores e pensamento empresarial (quadro 4) -, os quais foram definidos como as categorias de análise a priori para este estudo (figura 1).

\section{Categorias a priori}

Ressalta-se que cada categoria - figura 1 - foi analisada com base nas características comportamentais empreendedoras que evidenciem o foco definido pelos autores e que 
sustentam as referidas tipologias. As tipologias, por sua vez, foram definidas pelos autores a partir de características comportamentais especificas, as quais foram identificadas nos relatos dos entrevistados neste estudo. No entanto, nem todas as características comportamentais de cada tipologia foram encontradas, pois cada indivíduo possui sua singularidade.

A seguir apresentam-se as categorias de análise definidas a priori (quadro 5) - forma de atuação; personalidade e potencial para o sucesso; e valores e pensamento empresarial -, os tipos de empreendedores evidenciados e o enquadramento do comportamento de cada entrevistado nos três períodos de pesquisa.

\section{Quadro 5: Tipos de Empreendedor e o Insucesso Empresarial}

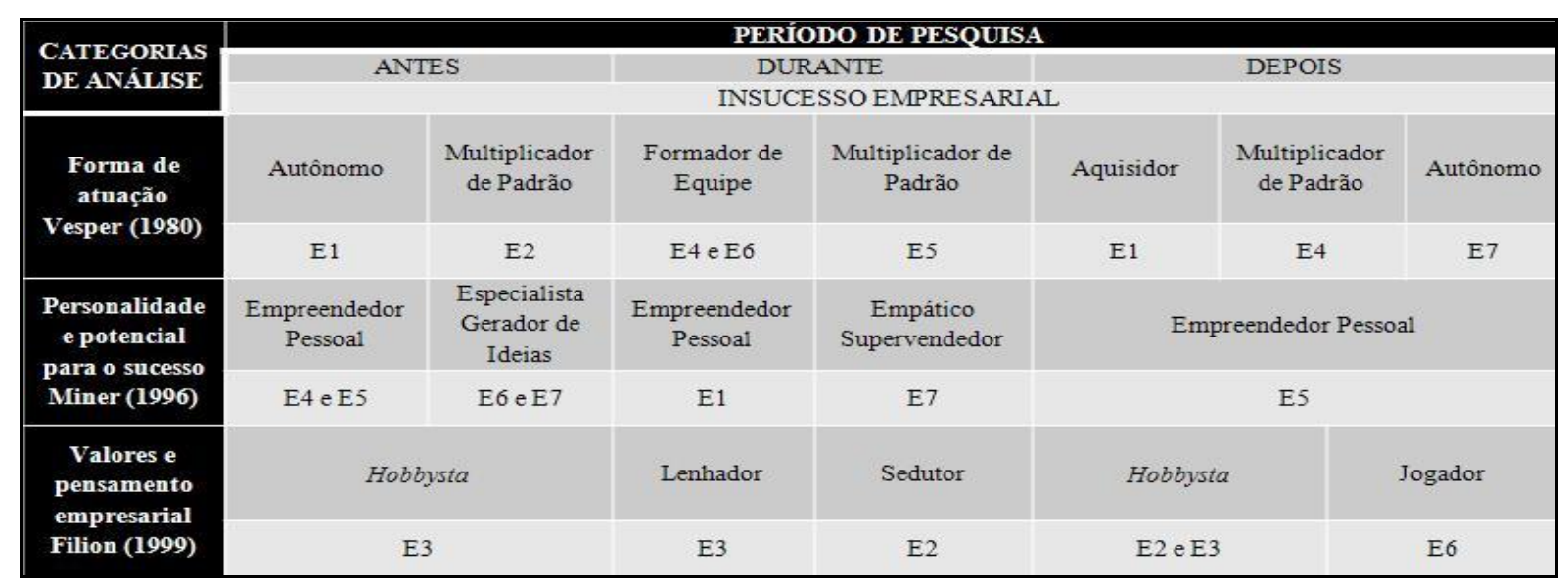

Fonte: Desenvolvido pelos autores.

Com base no quadro 5, pode-se constatar que os entrevistados apresentaram diferentes características comportamentais, pois seus tipos de empreendedor sofreram alterações nos diferentes momentos de pesquisa. Ressalta-se que os mesmos também poderiam ser caracterizados em outras tipologias; no entanto, para fins de análise dos resultados deste estudo, optou-se pela caracterização do perfil empreendedor apenas para o tipo de empreendedor mais evidente em cada entrevistado, no período de pesquisa - antes, durante e depois do insucesso empresarial.

A partir do exposto, no intuito de contribuir para a compreensão das mudanças de comportamento e tipo de empreendedor, apresentam-se a seguir as categorias a priori definidas para este artigo. Ressalta-se que a análise dessas categorias é apresentada para cada momento de pesquisa - antes, durante e depois do insucesso empresarial.

\section{Forma de atuação - Vesper (1980)}

Segundo Paulino e Rossi (2003) as características dos empreendedores, aliadas as suas experiências e personalidade, influenciam na forma como estes agem diante do contexto empresarial. Para Dornelas (2008), uma das características presentes no comportamento do empreendedor é a habilidade de identificar oportunidades no mercado para investir e montar um negócio. Nesse sentido, Hisrich, Peters e Shepherd (2009) relatam que os empreendedores têm necessidade de realização que, muitas vezes, é proporcionada pela constituição do seu próprio negócio.

Sob esta perspectiva, Vesper (1980) definiu em sua tipologia onze tipos de empreendedor, com base em sua forma de atuação, visando identificar parâmetros na maneira como os 
empreendedores tomam decisões, tanto para abrir novos negócios, quanto para gerenciar os já existentes.

Considerando-se os tipos propostos pelo autor, foram encontrados, antes do insucesso empresarial, a partir dos relatos dos entrevistados, os seguintes tipos de empreendedor: autônomo e multiplicador de padrão. 0 comportamento de E1 apresentou características do tipo autônomo, pois este empreendedor apresentou habilidades técnicas em serralheria, o que o motivou para iniciar seu próprio empreendimento e executar seus serviços pessoalmente. Já o tipo multiplicador de padrão, pode ser constatado no comportamento de E2 que, ao observar a inexistência de uma academia de ginástica em sua cidade, percebeu a oportunidade de negócio e o estruturou em busca da obtenção de lucro.

"Sempre fui esforçado, sempre me dediquei bastante naquilo que eu to fazendo é, então aprendi rapidamente a fazer portão, grade. E daí com 17 anos, aproximadamente, eu iniciei a minha própria serralheria, pedi a conta ele me deu a maquina de solda, uma maquina de corte, e eu iniciei com essas ferramentas que esse serralheiro havia me dado." (E1)

“... A primeira empresa que eu abri, na verdade a primeira coisa que eu fiz no passado, foi ter uma, uma academia de ginástica, gostava muito, e eu falei: ah, na cidade não tem, vou montar uma. Montei." (E2)

Durante o insucesso empresarial, considerando-se a tipologia de Vesper (1980), foram encontrados os seguintes tipos de empreendedores: formador de equipes e multiplicador de padrão. 0 tipo formador de equipes tem como propósito a formação de equipes e a delegação de tarefas, comportamento que pode ser percebido nos trechos das falas de E4 e E6. No caso de E4, evidencia-se que o entrevistado tinha sua principal atuação voltada para a área comercial, sendo que, para a área técnica, E4 formou uma equipe de trabalho responsabilizando-a pelas atividades pertinentes a essa área. No entanto, na perspectiva de E4, sua equipe percebeu sua falta de conhecimento sobre o trabalho da área técnica, e se aproveitou da situação no intuito de obter vantagem, como pode ser visto abaixo, no trecho do relato de E4. Já no caso de E6, o empreendedor contratou vendedores para expandir seu negócio, mas, como ele se envolvia em outras atividades, passou a ser roubado pela equipe. Esses empreendedores foram caracterizados, então, como formador de equipes; no entanto, pode-se perceber que suas atitudes e comportamentos com relação a sua equipe negligenciam sua atuação como empreendedor, pois davam pouca atenção ao gerenciamento e controle de suas equipes. Nesse sentido, alguns autores sugerem a existência de características no comportamento do empreendedor que podem levá-lo ao fracasso, dentre elas pode-se ressaltar a falta de conhecimento, a falta de habilidade em gestão e a insuficiência de dedicação (LEITE, 2001; DOTLICH e CAIRO, 2003; FINKELSTEIN, 2007; HISRICH, PETERS e SHEPHERD, 2009); o que pode ter influenciado para o insucesso empresarial dos empreendedores entrevistados. Os trechos das falas de E4 e E6 parecem ilustrar o enfoque abordado acima.

"Por que eu não sei se o pessoal não acompanha a minha velocidade de trabalho né, não tem o mesmo ritmo e acaba descontinuando a coisa e não dando certo, e foram varias decepções que eu tive na área... por que é uma área que eu entrei muito que eu não conhecia, eu vim de uma área completamente comercial e entrei numa técnica, quando o pessoal percebeu que eu não entendia o que eles faziam, então ai eles se aproveitaram do momento." (E4) 
"Eu monto uma equipe de vendedores. Eu comecei a trabalhar vários vendedores, e já não tinha mais tempo de sair pra vender, e sim de administrar o outro trabalho. Eu cheguei a ter de 60 a 80 vendedores, no interior do estado de São Paulo. Então acredito que até foi pior, porque o problema maior não foi a administração. Então passei, a ser roubado, pelos próprios vendedores." (E6)

Quanto ao tipo de empreendedor multiplicador de padrão, sua característica principal é a multiplicação de negócios visando a obtenção de lucro. 0 trecho do relato de E5 mostra características desse tipo, pois sempre que surgia uma oportunidade passível de lucro, ele direcionava sua atenção ao encontro dessa oportunidade, mesmo que não desse certo, mantinha este tipo de comportamento; como pode ser visto no relato abaixo.

“...daí de motorista passei a técnico de campo comercial, e tocava a escola de musica, eu sempre tive dois empregos, principalmente nas épocas que uma empresa quebrava, eu tinha que voltar pro mercado de trabalho, eu tinha que comer né." (E5)

Já no período posterior ao insucesso empresarial, foram encontrados os tipos de empreendedor denominados como aquisidor, multiplicador de padrão e autônomo, na perspectiva de Vesper (1980). O comportamento de E1 apresenta características do tipo aquisidor, pois o entrevistado visou a oportunidade de se inserir em um negócio que já estava em operação, isto é, fez uma proposta de parceria para a dona do brechó que a sua esposa frequentava. No que se refere ao comportamento de E4, o mesmo caracteriza-se como do tipo multiplicador de padrão, pois E4 comprava empresas falidas ou que estavam por fechar visando a obtenção de lucro. No caso de E7, seu comportamento apresentou características do tipo autônomo, visto que no momento em que se encontrava sem trabalho, teve o apoio de um amigo que o convidou para fazer consultoria em um centro de treinamento em informática, assim executava seu serviço, baseando-se nas habilidades técnicas que ele adquiriu durante a vivência de seu negócio. Como pode ser constatado nos trechos abaixo.

"Eu ia buscar a minha esposa em um brechó, quando cheguei lá conheci a dona, a dona trabalhava num espaço bem pequenininho, na casa dela, mas sempre como eu tinha uma visão ampla, eu visualizei ali, um crescimento, e propus pra ela ir num salão que tinha na minha casa [...] Aí eu disse, vamo lá, eu entro com o salão, a senhora entra com o fornecedor e a gente racha a mercadoria. E ela, tudo bem, é tudo que seu estou precisando. Então eu iniciei um negócio de coisas usadas." (E1)

"Comecei a crescer junto com a companhia, oportunidades de postos fechados, empresas falidas e a empresa viu a seriedade do nosso trabalho e começou a investir." (E4)

“Meu amigo tinha um centro de treinamento na área de informática, já me
conhecia há alguns anos, me respeitava, porque ninguém tem dúvida de como
eu sou, e aí ele me perguntou quanto que eu tava cobrando por hora de
consultoria, eu dei o valor e ele falou: 'Olha, eu te compro vinte e quatro
horas'. Eu não vou ser consultor, trabalhando pra um único cara eu não vou
ser consultor, né?! Mas ai a necessidade e tal, não sei o que, era uns, acho que
uns quatro, cinco mil. Vai fazer uma grande diferença quatro cinco mil." (E7)

Pode-se observar que, a partir da análise desta categoria, a forma de atuação dos empreendedores está diretamente relacionada às suas características comportamentais. Essas características determinam o comportamento do empreendedor, influenciando na 
maneira como este age diante do ambiente empresarial. Isso parece possibilitar a inferência de que o foco na forma de atuação do empreendedor, além de caracterizar a tipologia de Vesper (1980), sugere que o comportamento do empreendedor está intimamente atrelado aos seus interesses e percepções, fazendo com que o mesmo tenha ações distintas frente a situações adversas, como o insucesso empresarial.

\section{Personalidade e potencial para o sucesso - Miner (1996)}

Para Casado (2002), os estudos sobre o comportamento humano revelam que o ser humano é indivisível, e por este motivo pode ser considerado único. Em função disso, o seu comportamento apresenta características singulares que o distinguem de qualquer outro indivíduo. Uma dessas características são os traços de personalidade que, na visão de Cloninger (1999), se referem a um conjunto focalizado de particularidades em que é possível perceber o que leva uma pessoa a se comportar de maneira mais ou menos coerente.

Hall e Lindzey (1984) ressaltam o enfoque de Henry Murray, que sugere que a personalidade está relacionada com uma série de eventos que se estendem por toda a vida do indivíduo. Nesse sentido, a história de vida e os aspectos recorrentes e/ou novos do comportamento do indivíduo, influenciam de maneira significativa na formação de sua personalidade. Isto significa que a personalidade do indivíduo está atrelada ao contexto em que vive. Sua função é de integrar os conflitos e pressões as quais o indivíduo está exposto, de modo a satisfazer suas necessidades e a permitir que o indivíduo atinja objetivos futuros.

Evidenciando-se que a personalidade influencia e é influenciada pelo contexto, e que a percepção do indivíduo empreendedor, gera seu comportamento e caracteriza sua singularidade de atuação, pode-se sugerir que o tipo de empreendedor também é definido com base nas características comportamentais desses indivíduos. Portanto, essas características estão atreladas a sua personalidade, que, no caso de uma situação adversa como o fracasso nos negócios, influenciam o comportamento desse indivíduo fazendo com que o mesmo apresente características comportamentais distintas - antes, durante e depois do insucesso empresarial.

Os tipos de empreendedor com foco na personalidade do empreendedor, encontrados antes do insucesso empresarial, foram o empreendedor pessoal e especialista gerador de ideia. Pode-se perceber, nos trechos dos relatos de E4 e E5, que estes apresentaram comportamentos característicos do tipo empreendedor pessoal: o primeiro, por possuir iniciativa e comprometimento com a empresa, por ter aproveitado uma oportunidade para atingir seu objetivo de abrir a sua empresa; e, o segundo, procurava ser bom em tudo o que fazia no intuito de atingir o objetivo de ser o melhor em sua área. Quanto ao tipo especialista gerador de ideia, esta se caracteriza por comportamentos direcionados à busca de inovação, de inventividade, dentre outros aspectos; o que pode ser visualizado nos trechos dos relatos de E6 e E7. 0 comportamento de E6 mostra um desejo por ideias, sempre alerta em busca de crescimento; e, o de E7, pode ser relacionado à busca pela inovação, procura atingir as estratégias da empresa através de novos produtos, como o plano assistencial para informática.

“Na época eu fui empregado, visualizando opções o crescimento é a experiência positiva dos meus patrões e a oportunidade que surgiu no mercado, pra eu entrar acho que aí eu senti no momento e falei é agora, vou entrar porque acho que é a minha vez". (E4)

“...eu tenho muito de perfeccionista né, na maioria das vezes, ai eu falei, bom 
então eu tenho que ser o melhor na área..." (E5)

"Eu acho que a ideia de surgir, talvez seja porque nunca levantei, trabalhando dentro com alguém, a ideia maior era o crescimento, então, eu sempre fui uma pessoa assim, alerta, em termos de crescimento" (E6)

"A gente já não conseguia mais tocar uma assistência técnica por que não tinha peça pras coisas né?! $\mathrm{E}$ ai, nesse momento eu tive um momento de criatividade muito legal, montei um plano assistencial de saúde pra informática: Unimicro. Você levava o computador gratuitamente, a gente fazia consulta com ele quantas vezes fossem necessárias. Mas ai a gente cobrava a peça. Eu cheguei a ter quase cinco mil clientes nesse cadastro, ai eu abandonei porque eu não conseguia mais dar suporte". (E7)

Embora existam teorias que sustentem que a personalidade é imutável, existem outras que acreditam que a personalidade é formada ao longo da vida do indivíduo (ERIKSON, 1959; MURRAY, 1938). Nessa perspectiva, se podem resgatar as ideias de Erikson (1959) em relação ao desenvolvimento psicossocial do indivíduo. 0 autor evidencia que, para cada fase da vida, existem características que influenciam e determinam o comportamento do ser humano; no entanto, cada uma dessas fases representa um momento da vida do indivíduo e sua maneira de lidar com as situações que vivencia, sendo esse processo resultante de suas percepções e do que acredita - valores, crenças, experiências, dentre outros. Nesse sentido, o desenvolvimento psicossocial parece estar atrelado ao desenvolvimento da personalidade do indivíduo, visto que seu comportamento deriva de sua percepção, que tem sua origem nas concepções de cada um; da mesma forma que, Hall e Lindsay (1984), referenciando a concepção de Freud, afirmam que o comportamento do indivíduo está calcado na relação entre o id, ego e superego, os quais formam sua personalidade. Dessa forma, pode-se inferir que, aparentemente, a personalidade do indivíduo pode ser desenvolvida durante as fases desse desenvolvimento, e que influencia diretamente seu comportamento, sendo traduzida pela mudança de suas características comportamentais ao longo do tempo ou por meio de situações adversas, como no caso do insucesso empresarial.

Considerando-se um contexto de adversidade, como aquele que envolve o insucesso empresarial, o indivíduo empreendedor pode ser impactado de tal forma que sua personalidade pode ser afetada, visto que a desestruturação provocada por essa adversidade pode ser tão forte a ponto de o indivíduo não saber mais o que fazer, surgindo a possibilidade de uma ruptura no desenvolvimento de sua personalidade. Nesse período o comportamento do indivíduo está sendo questionado, assim como sua personalidade, conforme pode ser visto nos tipos de empreendedor apresentados a seguir.

Durante o insucesso empresarial foram encontrados os tipos empreendedor pessoal, em E1, e empático supervendedor, em E7. 0 comportamento de E1 enquadra-se no tipo empreendedor pessoal, que visa a realização de objetivos pessoais. Ao invés de reinvestir os recursos gerados pelo seu empreendimento, E1gastava dinheiro em função de sua satisfação pessoal, que na época era centrada em bens pessoais. 0 tipo empático supervendedor, que tem como foco as vendas, foi encontrada em E7, pois este empreendedor considerava que era um ótimo vendedor, no entanto, não dava a devida atenção à gestão administrativa.

"Eu não investi na empresa, todo o dinheiro que eu catei, ao invés de injetar dentro da empresa pra que ela viesse a crescer, não, eu injetei em mim. Roupa de marca, carro, é, boa curtição com as meninas que eu queria, e assim foi indo. Então eu deixei de investir, no crescimento da empresa, ao qual naquele 


\section{Mudança de comportamento de empreendedores: uma análise dos tipos de empreendedor antes, durante e depois do insucesso empresarial}

momento foi me entregue a oportunidade esse foi o fator fundamental, falta de visão". (E1)

"E ai assim, me tornei mó vendedor de blaster do, do Brasil né?! Fui homenageado várias vezes. Só que eu nunca gostei de administração, eu não gostei de ficar lá dentro sentado, fazendo conta. Então isso foi meu grande erro. Aí chegou o momento que eu tomei pé, que não descobri que eu tinha vendido muito, ganhado muito, mas eu tava devendo pra bancos. Tava devendo impostos, e tinha um passivo trabalhista." (E7)

Tanto o passado, quanto o presente são importantes na composição da personalidade do indivíduo, que é o agente organizador e administrador do indivíduo. Dessa forma, seu comportamento não pode ser estudado separadamente de sua personalidade, pois se trata de um dinamismo pessoal que abrange a história de vida e o meio e situações $\mathrm{m}$ que vivencia (MURRAY, 1938). Considerando-se essa perspectiva, em um momento de adversidade, o indivíduo muda de comportamento de acordo com suas percepções, concepções, assim como a sua personalidade, nos diferentes momentos de pesquisa.

Após o insucesso empresarial, puderam-se constatar na fala de E5, características comportamentais que o enquadram no tipo denominado empreendedor pessoal (MINER, 1996). Este tipo foi observado em E5, antes e depois do insucesso; pois ele continua com a visão de ser bom, acreditando que ele pode dar o melhor em tudo o que faz, como pode ser visto no trecho do relato de E5.

"Acho que essa minha empreendedora foi quase que um jogador, e acreditar no potencial de acertar aquele foco na frente. 0 que você quer? Quais são os resultados que você espera? depois vem a empreendedora, que forma a matriz disso aí, e acredita que você pode confiar no seu potencial, e saber que você que você pode mais que muita gente". (E5)

A definição das tipologias de Miner (1996), adotada para este artigo, apresenta como foco a personalidade do indivíduo, que segundo o autor, tem relação direta com o seu potencial para o sucesso empresarial. No entanto, pode-se perceber que a personalidade é dinâmica, podendo sofrer mutações ao longo da vida do indivíduo, ou até mesmo diante de situações inesperadas (MURRAY, 1938), como no caso do insucesso empresarial. Assim, na perspectiva de que a personalidade do empreendedor está em fluxo constante, da mesma forma está o seu comportamento, e, consequentemente, seu tipo de empreendedor também se modificou nos três períodos de pesquisa.

\section{Valores e pensamento empresarial - Filion (1999)}

Para Schwartz (2005), os valores possibilitam agregar distintos interesses em diversas ciências sobre o comportamento humano. Essa área de estudo evidencia aspectos da estrutura psicológica do ser humano (SCHWARTZ, 2005) que, segundo Caravantes (1984), gera o comportamento do indivíduo; estando o mesmo atrelado às suas concepções, que por sua vez, estão relacionadas às suas percepções. Nesse sentido, Schwartz (2005) sugere que os valores podem ser vistos como critérios usados pelos indivíduos para avaliar ações, pessoas e eventos.

Relacionando-se essa perspectiva com o comportamento do indivíduo empreendedor diante de seu negócio, Tamayo e Porto (2005) afirmam que os valores exercem um papel significativo que se traduzem em diversas atitudes e comportamentos manifestos no contexto do trabalho. Trata-se, portanto, de princípios e crenças que orientam a vida do indivíduo, e 
por consequência, influenciam as suas práticas, políticas e formação da estrutura da organização, direcionando assim, as escolhas estratégicas e o funcionamento do seu empreendimento (TAMAYO E PORTO, 2005).

Sob essa perspectiva, levando em consideração o foco - valores e pensamento empresarial pode-se constatar que, antes do insucesso empresarial, o tipo de Filion (1999) encontrado foi o hobbysta, que é aquele que vê no seu negócio, a possibilidade de autorrealização. No caso de E3, o empreendedor tinha um emprego fixo durante as manhãs e, às tardes ele se dedicava ao seu próprio negócio, que considerava bom, pois entrava muito dinheiro, comportamento característico do tipo hobbysta.

"Fui conversar com o patrão. Me sustentar e tal. Ai ele me propôs que eu trabalhasse, continuasse trabalhando meio período, e fizesse uma experiência, à tarde. Eu trabalhava até uma hora e a tarde eu saía, eu saía em São Paulo, Osasco, Campinas, entendeu? E saía nas casas, largava uma cartela, marcava pra voltar daqui trinta dias e daqui trinta dias você recebia o dinheiro, dava os dois prêmios né?! Pra mulher e pro, pra quem vendeu e pra quem comprou e ganhou, e eu trabalhei três meses, mas era tão bom cara, era tanto dinheiro que entrava..." (E3)

Para Filion (1993), os valores e o pensamento do empreendedor também podem estar condicionados ao seu sistema de relações, sua forma de liderança, sua sinergia e suas percepções, pois são fatores que contribuem para o desenvolvimento da visão do empreendedor, e por este motivo, podem estar atrelados ao sucesso o insucesso do negócio.

Durante o insucesso empresarial pode-se perceber a abordagem sobre valores no comportamento de E3, caracterizado pelo tipo lenhador, em que o empreendedor volta-se para a produção e não considera aspectos humanos. Esse comportamento é evidenciado em E3, quando culpa o sócio por não considerar a opinião de uma terceira pessoa para lançar um novo produto, o esmalte, por acreditar que a produção que eles tinham era o suficiente, começando assim, uma série de desentendimentos. Ainda nesse período, outro tipo encontrado foi o sedutor - que se entrega emocionalmente aos negócios -, como pode ser percebido no trecho do relato de E2. 0 comportamento desse empreendedor se justifica como sedutor em função deste se entregar de maneira emocional aos negócios, no entanto, perde o entusiasmo devido às insatisfações com o trabalho.

"Aos poucos você vai percebendo é... que você vai desligando por conta dessa
insatisfação da sociedade e você vai desanimando, é um processo de despego,
de desamor, desapego na empresa, até o momento onde eu também pensei na
possibilidade de um desligamento da parte de viagens." (E2)
"O que você produzia vendia, as lojas tavam procurando, o produto não tinha.
Você vendia tudo que fazia... tudo. Tinha quase vinte produtos na linha e eu
vendia os vinte, não tinha nenhum encalhado, então a preocupação é produzir.
O que veio trazer as dificuldades, o que veio trazer foi o relacionamento. Uma
vez uma pessoa falou: Ah, vocês estão bem, lança esmalte de unha, aí o sócio
falou: ah não, isso aqui ta bom, o que tem ai ta bom, não precisamos lançar
mais nada, tamo ganhando bem e tal... Assim começa né?! Ai já começou, uma
conseqüência do, do desentendimento..." (E3)

Filion (1993) ressalta que a história do indivíduo empreendedor - seus valores e modelos resultantes do seu passado familiar, sua experiência profissional, sua educação informal, suas crenças e seus sistemas de relações - influencia diretamente o seu negócio. Nesse sentido seu 
pensamento empresarial pode mudar de acordo com o seu momento de vida, especialmente diante uma adversidade como o insucesso empresarial, o que parece sugerir uma reflexão de seus valores que podem refletir na mudança de seu comportamento empreendedor.

Essa perspectiva pode ser evidenciada depois da vivência do insucesso empresarial nos trechos das falas de E2 e E3 que apresentaram comportamentos característicos do tipo hobbysta. No caso de E2, o seu negócio era o que ele realmente gostava de fazer e investia todos os recursos possíveis para desenvolvê-lo. Já E3, tinha outro emprego, mas dedicava todo o seu tempo e recursos ao negócio que lhe dava mais satisfação. Outro tipo encontrado neste período foi o jogador, evidenciada na fala de E6. Este tipo visa o negócio como um meio de ganhar o suficiente para realizar outros objetivos, como pode ser observado no trecho do relato de E6 - hoje ele considera a empresa como um suporte financeiro, um meio de ganhar o suficiente para fazer o que realmente quer, pois depois de toda sua experiência, sua prioridade é estudar.

"Não quero, não que eu não goste, acho muito bacana, trabalho na aviação civil é lido com isso, entendo, continuo encontrando com meus colegas que são da aviação civil da área de cargas de transporte de cargas, falo a respeito, mas assim, só o momento, acabou. Eu acho que é uma forma de eu me desligar daquela sociedade. Se eu penso, parece que eu to alimentando um processo que foi doloroso de depressão, e esse processo eu não quero mais". "Passei a ouvir mais a minha força interior, a minha voz interior, dou mais credibilidade a ela". (E2)

“Embalava os produtos na minha casa lá em Mogi, e punha no carro, vinha de manhã pro estacionamento, deixava ali, e o que vendia ficava ali, e fui indo... Comecei trabalhar. E começou melhorar, ai eu pensei 'nós precisamos arrumar um lugar', porque tinha vezes que eu ia duas vezes em Mogi, só de manhã saia de casa com mercadoria." (E3)

"Nunca me vi sem trabalhar, é o que eu não tenho hoje, é o prazer de ser milionário. Isso não me passa mais pela cabeça, o que eu tenho eu já resgatei. Resgatei minha casa, o meu carro, a minha família, que foi o mais importante. E a minha vida de agora em diante é estudar". (E6)

Nesse sentido, Cohen e Fink (2003) relatam que os valores pessoais determinam a atitude das pessoas, e que esta pode mudar no decorrer da vida. Isso pode ser observado nos relatos dos entrevistados que apresentaram tipos de empreendedor distintos nos diferentes momentos de pesquisa.

Sendo assim, constata-se que o comportamento e o tipo dos empreendedores entrevistados são diferentes, em sua maioria, nos três períodos de pesquisa - antes, durante e depois do insucesso empresarial. Considerando-se que as tipologias são definidas a partir de características comportamentais, como mencionado anteriormente, parece coerente afirmar que as mudanças no comportamento do indivíduo empreendedor, suscitam alterações em sua forma de atuação, em sua personalidade, e em seus valores e pensamento empresarial, o que consequentemente refletem alterações em seu tipo de empreendedor no período de pesquisa.

\section{Discussão dos Resultados}

Os resultados encontrados nesta pesquisa instigam a reflexão sobre a mudança do tipo e de características comportamentais de empreendedores no período de pesquisa - antes, durante e depois do insucesso empresarial. A discussão desses resultados traz consigo uma 
curiosidade a respeito dos fatores que levam esses indivíduos a mudarem sua forma de agir, de perceber o ambiente ao seu redor, e de rever seus valores e crenças, a partir da experiência do fracasso de seus negócios.

Nesse sentido, objetivando proporcionar uma melhor visualização das mudanças de tipo de empreendedor, criou-se o quadro 6 que sumariza os resultados encontrados. Como se pode observar, todos os entrevistados apresentaram alterações no seu tipo de empreendedor, considerando-se o período de pesquisa. Essas alterações consistiram na mudança de foco forma de atuação (VERSPER, 1980); personalidade e potencial para o sucesso (MINER, 1996); e, valores e pensamento empresarial (FILION, 1999) - e de tipo de empreendedor, o que evidencia por consequência, mudanças em suas características comportamentais.

\section{Quadro 6: Mudança de Tipo de Empreendedor diante do Insucesso Empresarial}

\begin{tabular}{|c|c|c|c|}
\hline \multicolumn{4}{|c|}{ TIPOS DE EMPREENDEDOR DIANTE DO INSUCESSO EMPRESARIAL } \\
\hline EMPREENDEDOR & ANTES & DURANTE & DEPOIS \\
\hline E1 & Autônomo & Empreendedor Pessoal & Aquisidor \\
\hline E2 & Multiplicador de Padrão & Sedutor & Hobbysta \\
\hline E3 & Hobbysta & Lenhador & Hobbysta \\
\hline E4 & Empreendedor Pessoal & Formador de Equipes & Multiplicador de Padrão \\
\hline E5 & Empreendedor Pessoal & Multiplicador de Padrão & Empreendedor Pessoal \\
\hline E6 & Especialista Gerador de Ideias & Formador de Equipes & Jogador \\
\hline E7 & Especialista Gerador de Ideias & Empático Supervendedor & Autônomo \\
\hline
\end{tabular}

Fonte: desenvolvido pelos autores.

Apesar da mudança de tipo ter sido constatada em todos os empreendedores entrevistados, pode-se observar uma situação peculiar nos casos de E3 e E5. Esses entrevistados apresentaram um tipo de empreendedor antes do insucesso empresarial, outro durante essa adversidade; porém, depois do insucesso, estes voltaram a apresentar características que os enquadraram no mesmo tipo de empreendedor identificado no período anterior ao insucesso.

Considerando a peculiaridade individual destes dois empreendedores, evidencia-se que E3, no período anterior ao insucesso, apresentou características que o definiram no tipo hobbysta - nesse tipo, o empreendedor tem a empresa como hobby, tendo um segundo emprego para dar apoio financeiro -, durante o insucesso, caracterizou-se no tipo lenhador - que tem como foco a produção - e, no período posterior, voltou a enquadrar-se no tipo hobbysta. Essas constatações podem significar que este empreendedor, especificamente, tinha sua empresa como um hobby, não se preocupando muito com os resultados que esta apresentava e sim, com sua satisfação pessoal, no entanto, quando se deparou com uma situação que poderia levar sua empresa ao fracasso, tentou focar sua atenção para a produção, no intuito de minimizar as consequências oriundas do fracasso de seu empreendimento. Diante dessa situação, o empreendedor não conseguiu evitar a descontinuidade de seu negócio. No período posterior ao insucesso empresarial, E3 voltou a apresentar as mesmas características comportamentais do momento vivenciado antes do insucesso, mantendo o mesmo foco valores e pensamento empresarial (FILION, 1999). Essa constatação parece contribuir para a inferência de que E3 manteve certo padrão comportamental no período de pesquisa, pois suas características comportamentais apresentaram similitudes, antes e depois do insucesso empresarial.

O outro empreendedor que apresentou características distintas dos demais foi o E5. Esse empreendedor além de ter seus tipos alterados, também mudou seu foco para definição das 
tipologias. No período anterior, E5 caracterizou-se como empreendedor pessoal (foco na personalidade e potencial para o sucesso) - esse tipo evidencia o comprometimento do empreendedor em relação aos seus interesses pessoais -, no período durante o tipo evidenciado foi o multiplicador de padrão (foco na forma de atuação) - reconhecem um negócio passível de ser multiplicado visando o lucro - e, no período posterior ao insucesso, o empreendedor tornou a apresentar o tipo empreendedor pessoal.

A partir do exposto até então, pode-se constatar que antes do insucesso empresarial o comportamento dos empreendedores entrevistados apresenta características que evidenciam sua forma de pensar, porém, sem a vivência da adversidade do fracasso. Essas características definem o comportamento desses indivíduos, o qual se apresenta como um interesse por objetivos pessoais, pela busca de novas ideias, sendo ele mesmo o responsável por implementá-las, dedicando seu tempo e sua energia aos negócios.

Durante o insucesso empresarial esse comportamento é influenciado pela experiência do fracasso, alterado em virtude da reflexão e do questionamento de seus valores e crenças. Nesse momento, pode-se constatar que o comportamento dos empreendedores entrevistados, em quase sua totalidade, apresenta focos distintos em relação ao período anterior ao insucesso. Essa perspectiva parece indicar que, durante o insucesso empresarial, em função da carga emocional envolvida nessa situação, o comportamento do empreendedor é acometido por uma série de pressões - sociais, financeiras, jurídicas, familiares, autoestima, dentre várias outras - que contribuem de maneira significativa para a reflexão mencionada acima e, consequentemente, alterando sua forma de agir. Nesse período, o comportamento dos empreendedores entrevistados caracteriza-se pelo esforço em direção à formação de uma equipe que dê suporte diante da adversidade do fracasso, o que parece sugerir a busca, de maneira desesperada, por uma solução para a situação que representa o fim de uma possível jornada pessoal e profissional.

Finalmente, após o insucesso empresarial, o comportamento desses empreendedores novamente sofre alterações, as quais evidenciam um comportamento caracterizado pela dedicação de todo o tempo livre para os negócios e pelo empenho na busca de seus objetivos, porém, de maneira focada e sem dispender energia em outras atividades que não estejam relacionadas aquilo que foi redefinido para sua vida. Contudo, constata-se que nem todos os empreendedores entrevistados apresentaram alterações em seus comportamentos, o que parece indicar que o insucesso de seu negócio pouco afetou ou alterou sua forma de agir, sugerindo que o indivíduo não percebeu a oportunidade de aprendizagem oriunda da adversidade do insucesso empresarial.

\section{Considerações Finais}

Considerando-se o objetivo do presente artigo - analisar a mudança de tipo e de características comportamentais de empreendedores antes, durante e depois do insucesso empresarial -, pode-se dizer que o mesmo foi alcançado. Tendo em vista que, por meio da análise dos dados, foi possível observar que os empreendedores entrevistados apresentaram mudanças de comportamento, o que acarretou na alteração de suas características comportamentais e, por sua vez, do tipo de empreendedor, em cada um dos momentos de pesquisa - antes, durante e depois do insucesso empresarial.

Isso parece sugerir que as fases pelas quais os empreendedores entrevistados passaram, diante do insucesso empresarial, influenciaram seu comportamento e, consequentemente, no enquadramento desse comportamento dentro dos diferentes tipos de empreendedor 
adotados para este artigo. Nesse sentido, o estudo do comportamento deste indivíduo pode contribuir, por meio da análise das categorias definidas a priori, para a compreensão de sua forma de atuação, de sua personalidade e de seus valores e pensamento empresarial, antes, durante e depois do insucesso empresarial.

Com relação ao foco forma de atuação, proposto na tipologia de Vesper (1980), os tipos de empreendedores encontrados antes do insucesso empresarial foram: autônomo e multiplicador de padrão. Durante o insucesso, também se pode observar o tipo multiplicador de padrão, juntamente do tipo formador de equipes. Por fim, depois do insucesso empresarial o comportamento dos entrevistados apresentaram características dos tipos de empreendedor: aquisidor, multiplicador de padrão e autônomo. Esta categoria sugere que o comportamento do empreendedor está intimamente atrelado aos seus interesses e percepções, fazendo com que o mesmo atue em seu negócio de acordo com as exigências do ambiente; contudo, diante da situação de insucesso empresarial, a atuação do empreendedor foi modificada, o que pode ser observado pelo reflexo das mudanças comportamentais sobre as alterações de tipo de empreendedor.

No que diz respeito ao foco personalidade e potencial para o sucesso, apresentado na tipologia de Miner (1996), as características comportamentais que definem o tipo empreendedor pessoal, podem ser constatadas nos três momentos de pesquisa. Sendo que antes do insucesso empresarial, este tipo de empreendedor foi encontrado, juntamente com o tipo especialista gerador de ideia; durante o insucesso, os tipos de constatados foram o empreendedor pessoal e o empático supervendedor; e, no período posterior ao insucesso, foi encontrado apenas o tipo de empreendedor, proposto por Miner (1996). Nesta categoria, também foi possível perceber alterações nos tipos de empreendedores, nos diferentes momentos de pesquisa, o que parece sugerir que houve mudança no comportamento dos entrevistados. Tendo em vista que o comportamento do indivíduo empreendedor é variável, sua personalidade também é dinâmica devido aos acontecimentos ao longo da vida, principalmente diante de situações adversas como o insucesso empresarial, conforme apresentado anteriormente.

E quanto ao foco valores e pensamento empresarial, apresentado por Filion (1999), o tipo hobbysta foi o tipo de empreendedor encontrado entre os entrevistados, antes do insucesso empresarial. Já durante o insucesso, puderam-se constatar os tipos de empreendedor lenhador e sedutor. Por fim, depois do insucesso, os tipos de empreendedor observados foram o hobbysta e o jogador. Nesta categoria pode-se perceber que as atitudes dos empreendedores se modificaram no decorrer da vivência do insucesso, o que refletiu no pensamento do empreendedor, na condução do seu negócio e nos seus valores pessoais que norteiam seu comportamento.

Esta perspectiva parece evidenciar o fato que a mudança de comportamento está relacionada ao contexto vivenciado e à percepção do indivíduo diante dele. Dessa forma, dependendo da maneira como ele absorve o impacto do fracasso determina, provavelmente, o tipo de comportamento que o empreendedor adota dentro desse contexto. Nesse sentido, pode-se constatar que a mudança de tipos de empreendedor, nos três momentos da pesquisa, está calcada na mudança de seu comportamento diante do contexto analisado, o que caracteriza sua forma de agir, de perceber e de decidir, evidenciando sua personalidade e seus valores.

Contudo, evidencia-se como limitação de pesquisa, o fato de os tipos de empreendedor apresentar, de modo geral, características comportamentais positivas, não evidenciando possíveis características comportamentais do empreendedor que podem contribuir para que 
seu negócio seja levado ao insucesso. Outro fato limitador é o número de tipologias utilizadas neste artigo, pois se sabe que as características comportamentais do empreendedor são bastante variáveis, já que se trata de comportamento humano. Além disso, ressalta-se que impossibilidade de generalização dos resultados aqui encontrados, sendo os mesmos aplicáveis apenas para o grupo de empreendedores entrevistados.

\section{Referenciais Bibliográficos}

BARDIN, L. Análise de Conteúdo. Lisboa: Edições 70, 2010.

BARON, R. A.; SHANE, S. A. Empreendedorismo: uma visão do processo. São Paulo: Thomson Learning, 2007.

BRUNO A. V.; LEIDECKER, J. K.; HARDER, J. W. Patterns of failure among Silicon Valley high technology firms. In: HORNADAY, J.; TARPLEY, F.; TIMMONS, J; VESPER, K.. Wellesley, Mass: Frontiers of entrepreneurial research. Babson Center for Entrepreneurial Research, 677-694, 1986.

BRUNO A. V.; MCQUARRIE, E. F.; TORGRIMSON, C. G. The evolution of new technology ventures over 20 years: patterns of failure, merger and survival. Journal of Business Venturing 7: 291-302, 1992.

CARAVANTES, G. R. Administração por objetivos: uma abordagem sócio-técnica. 3ª̣ed. Porto Alegre: Fundação para o desenvolvimento de Recursos Humanos, 1984.

CASADO, T. 0 comportamento das pessoas na organização. In: As pessoas na organização. 6a edição, p. 235-246. São Paulo: Gente, 2002.

CLONINGER, S. C. Teorias da Personalidade. São Paulo: Martins Fontes, 1999.

COHEN, A. R.; FINK, S. L. Comportamento organizacional: conceitos e estudos de casos. $7^{a}$ ed. Rio de Janeiro: Campus, 2003.

DORNELAS , J. C. A. Empreendedorismo: transformando ideias em negócios. Rio de Janeiro. Editora Elsevier, 2008.

DOTLICH, D. L.; CAIRO, P. C. Por que os executivos falham? Rio de Janeiro: Elsevier, 2003.

ERIKSON, E. Identity and the life cycle. Psychological Issues, vol 1, \#1. Adaptado por Dr. C. George Boeree (1997, 2006). Baseado em F. Rua, Psicologia, 120. ano: E. S. Nunes, 1959. publicado na página http://psychology.about.com/library/bl/blblio_erikson.html.

FILION, L. J. Visão e relações: elementos para um metamodelo empreendedor. Revista de Administração de Empresas. v. 33, p. 50-61, São Paulo, Nov/Dez, 1993.

Empreendedorismo: empreendedores e proprietários-gerentes de pequenos negócios. Revista de Administração, v.34, n.2, p. 05-28, abril/junho. São Paulo, 1999.

FINKELSTEIN, S. Os sete hábitos dos executivos "espetacularmente malsucedidos". In: VOGL, A. J. Anatomia do fracasso. HSMManagement, Vol. 1, n. 42, p.142 - 149, 2004.

. Por que executivos inteligentes falham. São Paulo: Makron Books, 2007.

FLECK, D. Archetypes of Organizational Success and Failure. Brasilian Administration 
Review (BAR), v. 6, n. 2, art. 1, p. 78-100, April/June. Curitiba, 2009.

GEM. Empreendedorismo no Brasil. Global Entrepreneurship Monitor, 2010.

HALL, C. S.; LINDZEY, G. Teorias da personalidade. 18ª̣ ed. São Paulo: EPU, 1984.

HISRICH, R. D.; PETERS, M. P.; SHEPHERD, D. A. Empreendedorismo. 7ํㅡ Ed. Porto Alegre: Bookman, 2009.

LEITE, E. F. 0 fenômeno do empreendedorismo e as empresas de base tecnológica. In Empreendedorismo: Competência Essencial para pequenas e médias empresas. ANPROTEC Associação Nacional de Entidades Promotoras de Empreendimentos de Tecnologias Avançadas. p. 84-102, Brasília, 2001.

MINER, J. B. Evidence for the Existence of a Set of Personality Types, Defined by Psychological Tests, that Predict Entrepreneurial Success. In: Frontiers of Entrepreneur Research, 1996 Edition, Babson College. Disponível em: $<$ www.babson.edu/entrep/fer/papers96/miner/>.

MURRAY, E. A. Explorations in Personality. New York: Oxford University Press, 1938.

PAULINO, A. D.; ROSSI, S. M. M. Um estudo de caso sobre o perfil empreendedor: características e traços da personalidade empreendedora. In: EGEPE - Encontro de estudos sobre empreendedorismo e gestão de pequenas empresas. Anais... Brasília: UEM/UEL/UnB, p. 205-220, Brasília, 2003.

PEREIRA, H. J.. Motivos de sucesso e de fracasso empresarial. In: Criando seu próprio negócio: como desenvolver o potencial empreendedor. Coordenação de Heitor José Pereira e Silva Aparecido dos Santos. Brasília: Ed. SEBRAE, p. 271-278, 1995.

RESENDE, E. O papel dos empresários no desenvolvimento do Brasil: suas 12 competências e 5 incompetências. São Paulo: Summus, 2008.

ROBINSON, S. Business failure rates: a look at sex and location. Academy of Entrepreneurship Journal; 13, 1; Entrepreneurship pg. 45, 2007.

SAMPIERI, R. H.; COLLADO, C. F.; LUCIO, P. B. Metodologia de Pesquisa. $3^{\text {a }}$ Ed. São Paulo: McGraw-Hill, 2006.

SCHUMPETER, J. A. Teoria do Desenvolvimento Econômico. Trad. Possa, M. S. Ed. Nova Cutural, São Paulo, 1997.

SCHWARTZ. S. H. Valores Humanos Básicos: seu contexto e estrutura intercultural. In: TAMAYO, Álvaro; PORTO, Juliana Barreiros. Valores e Comportamento nas Organizações.. Petrópolis, RJ: Vozes, 2005.

TAMAYO, A; PORTO, J. B. Valores e Comportamento nas Organizações. Petrópolis, RJ: Vozes, 2005.

VESPER, K. H. Perspectives on Entrepreneurship. In: New Venture Strategies. Chapter 1, p. 1-26. Englewood Cliffs: Prentice Hall, 1980.

ZACHARAKIS, A. L.; MEYER, G. D.; DECASTRO, J. Differing perceptions of new failure: a matched exploratory study of venture capitalists and entrepreneurs. Journal of Small 
Mudança de comportamento de empreendedores: uma análise dos tipos de empreendedor antes, durante e depois do insucesso empresarial

Business Management; Jul 1999; 37, 3; ABI/INFORM Global pg. 1, 1999.

ZAMPIER, M. A.; TAKAHASHI, A. R. W. Competências empreendedoras e proceso de aprendizagem empreendedora: modelo conceitual de pesquisa. Cadernos Ebape. v.9, edição especial, Rio de Janeiro, jul. 2011. 